\title{
A Comparison of Serve Speed and Motor Coordination between Elite and Club Level Tennis Players
}

\author{
by \\ Mustafa SÖĞÜT
}

\begin{abstract}
The purpose of this study was to compare the serve speed and motor coordination of elite and club level junior tennis players aged 11-14 years. Participants $(n=35)$ were assigned to one of the two groups according to their experience, weekly training volume and competition level. Serve speed was assessed with a sports radar gun. Motor coordination was evaluated by means of the Körperkoordinationstest für Kinder. The main results revealed that serve speed and motor coordination performance levels of the elite group were significantly higher than those of the club group. This study emphasized the importance of early participation and training intensity, which can play an important role in enhancement of serve speed and motor coordination.
\end{abstract}

Key words: serve speed, motor coordination, tennis.

\section{Introduction}

Tennis is considered to be one of the most popular sports in the world today. Increasing popularity and professionalism inspire sport scientists to carry out more research related to the factors affecting performance in tennis. These factors include stroke production, physical fitness, on-court movement and mental fitness (Groppel, 1992). According to Elliott and collaborators (2003), success in tennis is related to the effective combination of tennis strokes and on-court movements.

As mentioned in earlier studies (Bahamonde, 2000; Girard et al., 2005; Knudson et al., 2004), the serve is the most important stroke in tennis. It is very difficult to excel in the serve motion as it requires both complex coordination of the upper and lower body (Bahamonde, 2000; Wong et al., 2014) and precise use of major muscles (Knudson et al., 2004). According to Elliott (2006) producing high speed tennis serve requires a proper kinetic chain which involves sequential activation and coordination of different body parts (leg, trunk, shoulder, elbow, and wrist). During the last few decades, changes in racquet technology and training methods have made tennis players and coaches at all competitive levels to pay more attention to the power and velocity of the ball (Abrams et al., 2011). Martin et al. (2013) claimed that producing high velocity, especially during the serve, played an important role in successful play. Therefore, regardless of the sports level, all tennis players need to strive for a higher serve speed (Elliott et al., 1995).

The improvements in technology have also stimulated changes in the physical performance of players (Sánchez-Muñoz et al., 2007). These changes have forced modern tennis players to focus on versatile physical fitness training, and thus, to become more athletic (Reid et al., 2003). Previous studies reported the relationship between physical fitness and motor

1 - Kırıkkale University, Faculty of Sport Sciences, Kırıkkale, Turkey. 
competence (Cattuzzo et al., 2016; Stodden et al., 2009; Vedul-Kjelsås et al., 2011), the latter of which was described as the proficiency of physical skills and movement patterns (Castelli and Valley, 2007). According to Bardid et al. (2015) motor competence in childhood is an important factor in the determination of physical fitness characteristics in later life. Motor competence depends on motor coordination, which is defined as the dexterity to coordinate movements of multiple body parts while the body is in motion (Magill, 2003). It involves rapid body movement during the execution of various fundamental skills (Gallahue and Ozmun, 1995). Well-developed coordination not only allows tennis players to control their body parts in space and time, but also yields successive stroke production (Farrell and van de Braam, 2015).

Although serve speed and motor coordination have been widely investigated in the scope of sports science literature, there is limited information on the discrepancies between tennis players from different performance levels. The present study aimed to fill this gap through analyzing the differences between elite and club level junior tennis players of both genders. It was hypothesized that elite players would obtain better scores on serve speed and motor coordination than their club counterparts.

\section{Material and Methods}

\section{Participants}

The participants were elite and club level junior tennis players of both genders. The elite group consisted of children who were intensively participating in tennis and fitness training and competed in both national and international tournaments. The club group included children who were attending training moderately and competed irregularly in varied regional and national tournaments. The anthropometric and training characteristics of the participants are presented in Table 1. The participants were informed of the purpose of the study and the testing procedures. Informed consent forms were signed by their parents.

\section{Measures}

A radar gun (SR3600; Sports-radar, Homosassa, FL, USA) was used to assess the serve speed of the participants. Gross motor coordination performance levels of the participants were determined using a revised version of the Körperkoordinationstest für Kinder (KTK). The KTK (Kiphard and Schilling, 2007) includes four subtests: walking backward (KTKBeam), hopping (KTKнор), moving sideways (KTKBoard), and jumping sideways (KTK Jump $_{\text {). Each }}$ subset of scores was converted to a motor quotient that was adjusted to age and gender. Total KTK motor quotient (TotalкткмQ) scores enable the classification of gross motor coordination performances into five levels (Table 2).

\section{Procedures}

All measurements were performed at an indoor tennis court. Participants were asked to complete a standard warm up. The radar gun was mounted on a tripod and located behind the participants. Each participant was encouraged to serve with the highest speed from the deuce court in $30 \mathrm{~s}$ intervals. Eight successful serves were recorded and the one with highest speed was used for further analysis.

The KTK was administered according to the protocol described in the reference manual (Kiphard and Schilling, 2007). The participants were tested individually after they had been familiarized with the tasks. The KTKBeam test involved three balance beams that were $3 \mathrm{~m}$ long with different widths $(3 \mathrm{~cm}, 4.5 \mathrm{~cm}$ and $6 \mathrm{~cm}$ ). Participants were asked to walk backward 3 times on each balance beam; the maximum number of steps for each beam was 8 . The maximum score was 72. For the KTKHop test, the participants were required to hop on one leg over foam obstacles (height ranging from 0 to $60 \mathrm{~cm}$ ). The maximum score was 78 . In the KTK $K_{\text {Board }}$ test, participants moved their body sideways from one board to another for $20 \mathrm{~s}$. The score was the sum of the two trials. In the KTKJump test, participants were asked to jump laterally over a wooden rod $(2 \mathrm{~cm}$ in height) for $15 \mathrm{~s}$. The score was the sum of the two trials. Finally, the raw scores for each subtest were converted into motor quotient scores to determine the Totalкткме.

Analysis

Since the normality and homogeneity of variance assumptions failed, the non-parametric Mann-Whitney U test was performed to analyze the possible serve speed and motor coordination performance differences between the groups of both genders. 


\section{Results}

Serve speed and motor coordination performance results of the participants are presented in Table 3. The results showed that both male $(\mathrm{U}=14.00, p<.05)$ and female $(\mathrm{U}=2.50, p<$ .01 ) elite players had significantly higher serve speed scores than the club players. Motor coordination performances of male $(\mathrm{U}=5.00, p<$ $.01)$ and female $(U=4.50, p<.01)$ subjects from the elite group were also significantly better than those of the other group. Considering the raw scores, only KTKHop $(U=13.50, p<.05)$ and
$\mathrm{KTK}_{\text {Board }}(\mathrm{U}=5.50, p<.01)$ for elite boys and only $\mathrm{KTK}_{\text {Board }}(\mathrm{U}=13.00, p<.05)$ and $\mathrm{KTK}_{\mathrm{Jump}}(\mathrm{U}=2.00$, $p<.01)$ for elite girls were significantly different from those of their club counterparts among the subtests of the KTK.

The distribution of motor coordination levels of the participants is given in Table 4. According to the classification by Kiphard and Schilling (2007), none of the participants scored under the normal level.

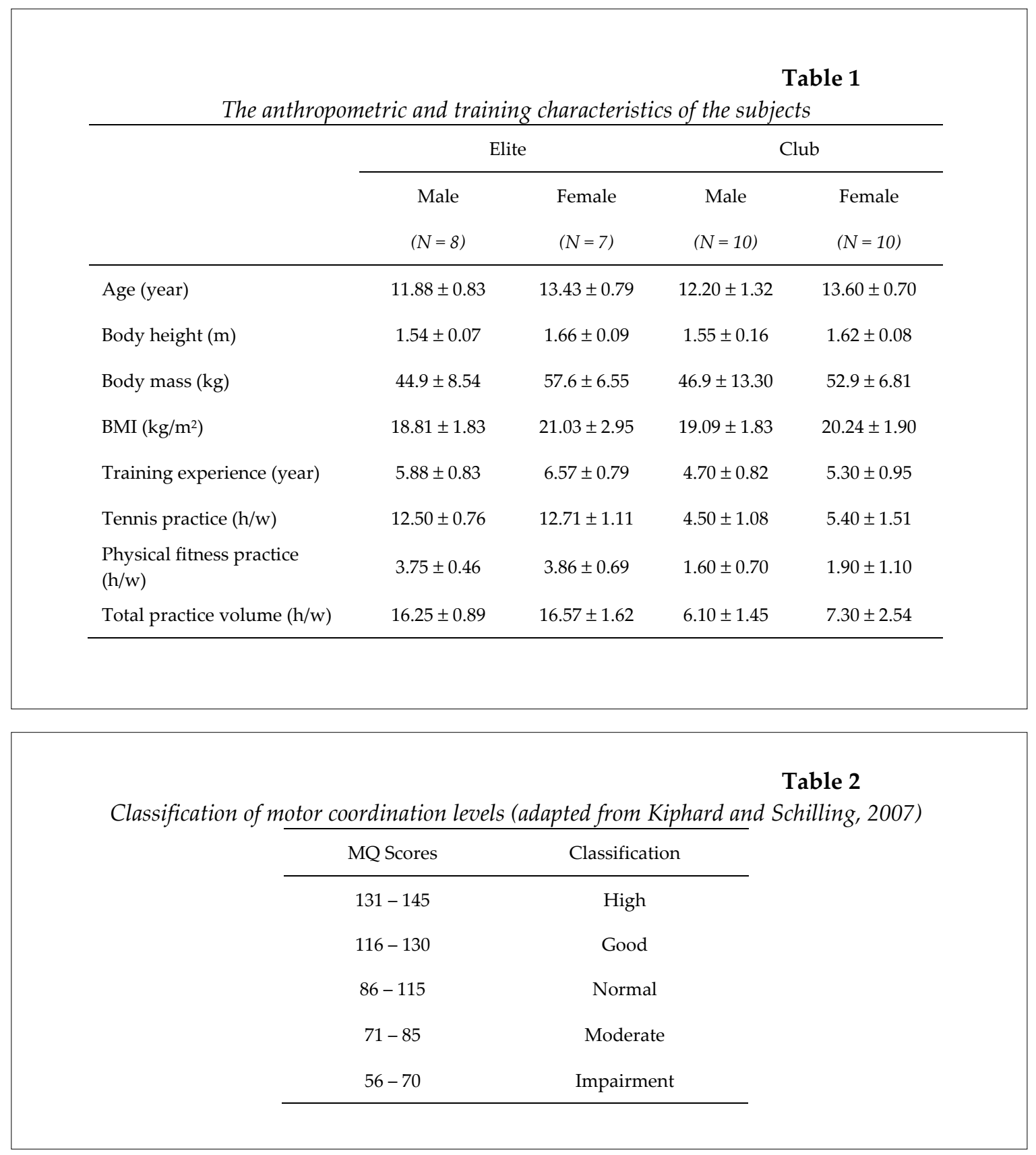




\begin{tabular}{|c|c|c|c|c|}
\hline \multicolumn{5}{|c|}{ Serve speed and motor coordination performance scores of participants } \\
\hline & \multicolumn{2}{|c|}{ Elite Group } & \multicolumn{2}{|c|}{ Club Group } \\
\hline & Male & Female & Male & Female \\
\hline $\begin{array}{l}\text { Serve speed } \\
(\mathrm{km} / \mathrm{h})\end{array}$ & $135.63 \pm 9.27$ & $149.29 \pm 11.19$ & $118.80 \pm 16.05$ & $125.40 \pm 13.07$ \\
\hline КTKвеam & $60.50 \pm 8.62$ & $63.00 \pm 7.02$ & $48.00 \pm 14.11$ & $53.00 \pm 13.70$ \\
\hline КTKнор & $75.75 \pm 3.28$ & $76.43 \pm 3.31$ & $66.20 \pm 8.12$ & $72.10 \pm 8.03$ \\
\hline KTKBoard & $56.00 \pm 3.30$ & $55.29 \pm 6.85$ & $49.10 \pm 4.07$ & $51.10 \pm 3.81$ \\
\hline $\mathrm{KTK}_{\text {Jump }}$ & $95.63 \pm 8.05$ & $100.14 \pm 5.49$ & $90.30 \pm 4.64$ & $89.10 \pm 4.82$ \\
\hline Totalкткме & $122.38 \pm 6.44$ & $117.57 \pm 8.58$ & $109.10 \pm 8.17$ & $103.40 \pm 4.99$ \\
\hline
\end{tabular}

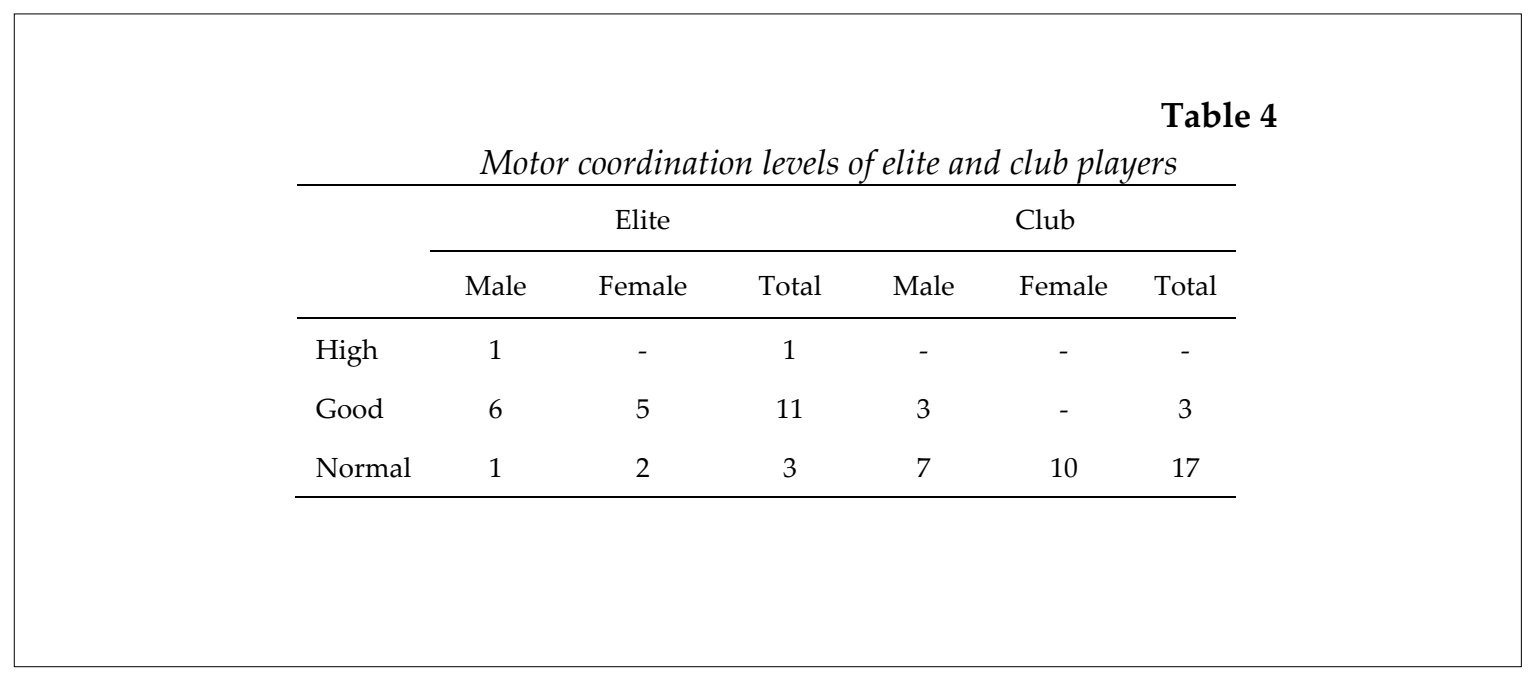

\section{Discussion}

The purpose of this study was to compare the serve speed and motor coordination of junior tennis players from different performance levels. It was hypothesized that both elite male and female players would attain higher scores on the tested parameters than their club counterparts. The results of the study supported the hypothesis that elite players had significantly superior scores on both tasks compared with club players.

Considering the serve speed scores, the results are in accordance with the findings of Girard et al. (2005) who analyzed the lower-limb activity during the power serve of male tennis players (age $=21.5$ 3.8). They ranked and divided their participants into three sub-groups: beginners (recreational players), intermediate (good club players), and elite athletes (national level players). Their results indicated that serve speed was higher in elite players (169.4 11.3 $\mathrm{km} / \mathrm{h})$ compared to beginners $(107.26 .1 \mathrm{~km} / \mathrm{h})$ and intermediate players (148.8 $16.3 \mathrm{~km} / \mathrm{h}$ ). Supportive findings were also reported by Bartlett et al. (1995) who compared three-dimensional analyses of serves between national and county level tennis players. The mean post-impact ball speed of national players was found to be much 
faster than that of county players. According to Girard et al. (2005), preloaded muscles and the use of leg extensor muscles are the major determinants in the production of effective high speed tennis serves by skilled players. Additionally, results demonstrated that the mean serve speed score of female players was better compare to that of their male counterparts in both groups. This finding might be explained considering the age disparity as female players are older than male players in both elite and club group.

As revealed by the results, none of the participants in either group performed at lower than normal levels of motor coordination, which is in line with the findings of Vandorpe et al. (2012) who evaluated motor coordination levels of elite $(\mathrm{n}=12)$ and sub-elite $(\mathrm{n}=11)$ female gymnasts using the KTK. The mean motor quotient scores of the participants were found to be above normal levels for both groups (elite = 133.74 .3 and sub-elite $=129.4 \quad 5.3$ ). It was suggested that a non-sport-specific motor coordination test might be valuable for the early identification of talent in gymnastics and other sports (Vandorpe et al., 2012).

Motor coordination scores of players in the elite group were significantly higher than these of players in the club group. These results are supported by the findings of Opstoel et al. (2015). They compared motor coordination differences in 9- to 11-year-old children who had low, moderate and high training volumes. Subjects were selected from 25 different sports that were categorized as athletics, ball sports, dance, gymnastics, martial arts, racquet sports, swimming and other sports. It was found that regardless of the type of sport, children who had a high volume of training demonstrated superior motor coordination performance. In support of these findings, Fransen et al. (2012) assessed motor coordination of 735 male children who participated in multiple or single sports in three age groups (6-8 years, 8-10 years, and 10-12 years). The KTK was used to assess motor coordination. The mean motor coordination scores of children participating in multiple sports were higher compared to children participating in a single sport for all age groups.

Regarding the raw scores of the subtests, generally elite players obtained better mean scores. However, no significant difference was found in the walking backward test between elite and club groups of both genders. Bardid et al. (2015) noted that the walking backward task did not depend on physical fitness, whereas the other three tests required strength, speed, endurance, and flexibility.

In conclusion, the study highlighted the serve speed and motor coordination differences between elite and club level junior tennis players. These findings can be explained by the sport specific experience and weekly training volume of players. Subjects in the elite group not only had more experience, but also had greater amounts of weekly tennis and conditioning training. It can be concluded that participating intensively in tennis training at an early age might play an important role in the enhancement of serve speed and motor coordination performance of a junior tennis player. It must be noted that the study was limited to a small sample size. The results would be more valid with a larger sample. Further studies that focus on the predictability of the KTK for long term success in tennis are recommended.

\section{References}

Abrams GD, Sheets AL, Andriacchi TP, Safran MR. Review of tennis serve motion analysis and the biomechanics of three serve types with implications for injury. Sports Biomech, 2011; 10(4): 378-390

Bahamonde RE. Changes in angular momentum during the tennis serve. J Sports Sci, 2000; 18(8): 579-592

Bardid F, Rudd JR, Lenoir M, Polman R, Barnett LM. Cross-cultural comparison of motor competence in children from Australia and Belgium. Front Psychol, 2015; 6: 964

Bartlett RM, Filler J, Miller S. A three-dimensional analysis of the tennis serves of national (British) and county standard male players. Science and Racket Sports, 1995; 98-102

Castelli DM, Valley JA. The relationship of physical fitness and motor competence to physical activity. J Teach Phys Educ, 2007; 26 (4): 358-374 
Cattuzzo MT, dos Santos Henrique R, Ré AHN, de Oliveira IS, Melo BM, de Sousa Moura M, de Araújo RC, Stodden D. Motor competence and health related physical fitness in youth: A systematic review. J Sci Med Sport, 2014; 19: 123-129

Elliott B. Biomechanics and tennis. Br J Sports Med, 2006; 40: 392-396

Elliott BC, Marshall RN, Noffal GJ. Contributions of upper limb segment rotations during the power serve in tennis. J Appl Biomech, 1995; 11: 433-442

Elliott BC, Reid M, Crespo M. Biomechanics of advanced tennis. London, United Kingdom: ITF Ltd, 2003

Farrell P, van de Braam M. Developing co-ordination for under 10 players. ITF Coaching and Sport Science Review, 2015; 65(23): 8-9

Fransen J, Pion J, Vandendriessche J, Vandorpe B, Vaeyens R, Lenoir M, Philippaerts RM. Differences in physical fitness and gross motor coordination in boys aged 6-12 years specializing in one versus sampling more than one sport. J Sports Sci, 2012; 30(4): 379-386

Gallahue DL, Ozmun JC. Understanding motor development. Infants, children, adolescents, adults. (3rd ed). Madison, WI: Brown \& Benchmark; 1995

Girard O, Micallef J, Millet G. Lower-limb activity during the power serve in tennis: effects of performance level. Med Sci in Sports Exerc, 2005; 37: 1021-1029

Groppel JL. High tech tennis, 2nd edn. Champaign, IL: Leisure Press; 1992

Kiphard EJ, Schilling F. Körperkoordinationstest für kinder: KTK. Beltz-Test; 2007

Knudson DV, Noffal GJ, Bahamonde RE, Bauer JA, Blackwell JR. Stretching has no effect on tennis serve performance. J Strength Cond Res, 2004; 18(3): 654-656

Magill RA. Motor learning and control: Concepts and applications. New York, McGraw-Hill; 2003

Martin C, Kulpa R, Delamarche P, Bideau B. Professional tennis players' serve: correlation between segmental angular momentums and ball velocity. Sports Biomech, 2013; 12(1): 2-14

Opstoel K, Pion J, Elferink-Gemser M, Hartman E, Willemse B, Philippaerts R, Visscher C, Lenoir M. Anthropometric characteristics, physical fitness and motor coordination of 9 to 11 year old children participating in a wide range of sports. PloS One, 2015; 10(5): e0126282

Reid M, Quinn A, Crespo M. ITF Strength and conditioning for tennis. London: ITF; 2003

Sánchez-Muñoz C, Sanz D, Zabala M. Anthropometric characteristics, body composition and somatotype of elite junior tennis players. Br J Sports Med, 2007; 41(11): 793-799

Stodden D, Langendorfer S, Roberton MA. The association between motor skill competence and physical fitness in young adults. Res $Q$ Exerc Sport, 2009; 80(2): 223-229

Vandorpe B, Vandendriessche J, Vaeyens R, Pion J, Matthys S, Lefevre J, Philippaerts R, Lenoir M. Relationship between sports participation and the level of motor coordination in childhood: A longitudinal approach. J Sci Med Sport, 2012; 15: 220-225

Vedul-Kjelsås V, Stensdotter AK, Sigmundsson H. Motor competence in 11-year-old boys and girls. Scand J Educ Res, 2013; 57(5): 561-570

Wong FK, Keung JH, Lau NM, Ng DK, Chung JW, Chow DH. (2014). Effects of body mass index and full body kinematics on tennis serve speed. J Hum Kinet, 2014; 40(1): 21-28

\section{Corresponding author:}

\section{Mustafa SÖĞÜT}

Kırıkkale University, Faculty of Sport Sciences, Kırıkkale, Turkey

Phone: +903183574242

E-mail: msogut@kku.edu.tr 